\title{
PATRIMÔNIO IMATERIAL: REFLEXÕES SOBRE A REBELDIA DA MATÉRIA
}

\author{
ANA CLARA DE REBOUÇAS CARVALHO \\ http://orcid.org/0000-0002-3976-1857 \\ Universidade Federal da Bahia
}

RESUMO O debate contemporâneo sobre patrimônio, em suas múltiplas nuances, tem enfatizado a chamada dimensão imaterial das mais diversas culturas desde o nascer do novo século. Este artigo objetiva contribuir com estas trocas a partir de problematizações em torno da emblemática dicotomia: de um lado o mundo da cultura material, do outro, tudo aquilo que vem se compreendendo em termos de imaterialidade. Em abordagem ensaísta, o texto estrutura-se em dois momentos confluentes: um que contempla reflexões em torno da dimensão (i)material de duas experiências artísticas, e em diálogo com proposições de Ingold (2015) e Tarde (2007), outro, que busca aprofundar os desdobramentos das abordagens ali em relevo, agregando aí a dimensão ética proposta por Jonas (2006). Os principais eixos reflexivos aqui propostos enfocam a natureza contraditória da dualidade material/imaterial, bem como o que é posto em termos dos "pontos cegos" decorrentes ou vinculados em alguma medida a tal polarização, a exemplo dos riscos de aprofundamento dos desafios geralmente encontrados pelas políticas patrimoniais. Ademais, este artigo visa estimular a inclusão de perspectivas pouco usuais ao debate patrimonial, sobretudo, em seus desdobramentos éticos, pragmáticos e políticos.

Palavras-Chave: Patrimônio imaterial. Cultura material. Imaterialidade.

\section{ABSTRACT IMMATERIAL HERITAGE: REFLECTIONS ON THE REBELLIOUSNESS OF MATTER}

The contemporary debate about heritage, in its many nuances, has emphasized the immaterial dimension of the most diverse cultures since the dawn of the new century. This article aims to contribute to these exchanges from problematization around the emblematic dichotomy: on the one hand the world of material culture, on the other, everything that has been understood in terms of immateriality. In an 
essayistic approach, the text is structured in two confluent moments: one that contemplates reflections around the (im)material dimension of two artistic experiences, and in dialogue with propositions of Ingold (2015) and Tarde (2007), another, which seeks to deepen the unfolding of the approaches there, adding the ethical dimension proposed by Jonas (2006). The main reflective lines proposed focus on the contradictory nature of material / immaterial duality, and the "blind spots" related to such polarization, such as the risks of deepening the challenges often encountered by heritage policies. In addition, this article aims to encourage the inclusion of unusual perspectives on the heritage debate, especially in its ethical, pragmatic and political developments.

Keywords: Immaterial heritage. Material culture. Immateriality.

\section{RESUMEN}

\section{PATRIMONIO INMATERIAL: REFLEXIONES SOBRE LA REBELIÓN DE LA MATERIA}

El debate contemporáneo sobre el patrimonio, en sus múltiples matices, ha enfatizado la dimensión inmaterial de las culturas más diversas desde los albores del nuevo siglo. Este artículo tiene como objetivo contribuir a estos intercambios desde la problematización en torno a la dicotomía emblemática: por un lado, el mundo de la cultura material, por otro, todo lo que se ha entendido en términos de inmaterialidad. En un enfoque ensayístico, el texto se estructura en dos momentos confluentes: uno que contempla reflexiones en torno a la dimensión (in)material de dos experiencias artísticas, y en diálogo con las proposiciones de Ingold (2015) y Tarde (2007), otro, que busca profundizar estos enfoques, agregando la dimensión ética propuesta por Jonas (2006). Las principales líneas reflexivas propuestas se centran en la naturaleza contradictoria de la dualidad material / inmaterial, así como en lo que se expresa en términos de "puntos ciegos" que surgen o están relacionados en cierta medida con esta polarización, como en el caso de los riesgos de profundizar los desafios a menudo vistos entre políticas culturales. Además, este artículo tiene como objetivo fomentar la inclusión de perspectivas inusuales en el debate del patrimonio, especialmente en sus desarrollos éticos, pragmáticos y políticos.

Palabras clave: Patrimonio inmaterial. Cultura material. Inmaterialidad. 


\section{Notas introdutórias}

O debate acerca de "patrimônio" tem sido intenso no vasto campo das ciências e para além dele, sobretudo, desde o século XIX, em suas radicais transformações em múltiplos campos. Para Choay (2001), trata-se de uma "bela palavra, antiga e enraizada no espaço e no tempo", mas também um conceito "nômade", dadas as suas diversas e complexas inserções (patrimônio histórico, patrimônio natural, patrimônio genético, cultural, material, entre outras), e que segue "trajetória diferente e retumbante" que outrora, conforme aquela autora discorre em termos de uma "alegoria do patrimônio", em sua renomada obra.

Século XXI, e um breve sobrevoo em um importante portal de periódicos científicos revela mais de 30 mil ocorrências a partir do único termo "patrimônio". Ao agregar outras complexas dimensões, a exemplo da ética ou da cultura, é notória uma queda vertiginosa naquele número, o que não significa necessariamente um silenciamento ou uma despreocupação com tais aspectos, no entanto, confirma a intensa dinâmica e diversidade que incidem sobre tal debate.

É, portanto, bastante disponível uma literatura acerca dos processos de mudanças em torno da noção de "patrimônio", bem como a difusão desta entre os mais diversos contextos, inclusive, de modo não exclusivo e interdisciplinar, tal como pontuaram Souza e Crippa (2011, p. 238). Neste bojo, Lima (2012, p. 35), ao revisar importantes referenciais acerca da temática, detalha as "modulações que lhe foram sendo agregadas" ao longo do tempo e a partir das múltiplas reflexões multidisciplinares, a ponto de chegar à contemporaneidade enquanto uma expressiva diversidade de "territórios de ação indicados pelos títulos", a

1 Trata-se aqui do Portal Capes de Periódicos, com acesso e pesquisa em 10 de novembro de 2019. exemplo do que se pode conceber como "patrimônio arquitetônico", ou "patrimônio urbanístico", ou "etnográfico", ou "paleontológico", ou "científico", entre outros (LIMA, 2012, p. 35).

Em face disso, este artigo visa contribuir com tais reflexões, mais precisamente, a partir do que se convencionou chamar de "patrimônio imaterial". Nessa perspectiva, e de acordo com Lima (2012, p. 36), justo em meio aos processos de ampliação e aprofundamento do conceito de patrimônio, "ocorreu consolidarse a tipologia Patrimônio Intangivel" através da emblemática "Convenção para Salvaguarda do Patrimônio Cultural e Imaterial", da Organização das Nações Unidas para a Educação, a Ciência e a Cultura (UNESCO), em 2003. Ainda para aquela autora, e em que pese o "lento processo cultural" para a incorporação desta categoria enquanto "integrante da questão patrimonial", o seu reconhecimento "firmou-se no foco internacional" (LIMA, 2012, p. 36). Em termos de definição, a UNESCO (2003) assim o concebe:

Entende-se por patrimônio cultural imaterial as práticas, representações, expressões, conhecimentos e saber-fazer - assim como os instrumentos, objetos, artefatos e espaços culturais que thes são associados - que as comunidades, os grupos e, em alguns casos, os indivíduos reconhecem como fazendo parte de seu patrimônio cultural. (UNESCO, 2003)

Já nessas linhas, fica patente a impureza do conceito, isto é, a imaterialidade parece não se depurar dos vestígios materiais; e as controvérsias acerca disso não são de agora. Assim, tal como há uma literatura relativamente farta acerca de "patrimônio" amplo senso, o mesmo pode ser dito em relação às noções de "imaterial" e de "imaterialidade", as quais, a propósito, subjazem à definição acima. Ou seja, bem anterior àquela Convenção, as construções em torno do que se compreende, ou de que se admite enquanto "imaterial" ganham fôlego, ao 
menos, na arena das ciências sociais e humanas, desde as últimas décadas do século XX.

Não sendo em si mesma uma novidade inaugurada por uma organização internacional, a questão da imaterialidade vem suscitando novas e velhas inquietações no cenário dos complexos desafios patrimoniais na contemporaneidade, sendo, inclusive, uma espécie de "lugar comum" a constatação da indissociabilidade das dimensões material e imaterial, sobretudo, no âmbito das práticas. Esta é, talvez, a mais proeminente, ou, de certo, a mais persistente das inquietações: a já esgarçada polaridade entre "materialidade" e "imaterialidade", que então se institucionaliza a partir da criação de uma categoria técnico-conceitual como a de "patrimônio cultural imaterial", em suas pretensões universalizantes ou de alguma validade global.

Em face disso, os mais recentes debates parecem buscar novos posicionamentos em relação às demandas que emergem daquela famigerada e pouco convincente dualidade. Tanto assim que, Souza e Crippa (2011, p. 237), ao revisarem os discursos e as condições que produziram historicamente a referida dicotomia, buscam demonstrar de que se trata mais de uma "oposição apenas circunstancial" e menos uma sustentável dicotomia na "relação da sociedade com os seus produtos culturais".

Esses autores, em diálogo com seus pares, confirmam a falta de sentido em "uma separação entre patrimônio tangivel e intangivel ou objeto e processo", uma vez que "ele só se explica nesta relação"; e ainda defendem a perspectiva de "patrimônio como processo" enquanto "uma ideia que supera a oposição material-imaterial" (SOUZA e CRIPPA, 2011, p. 247). Todavia, a insistente dualidade em questão parece não desaparecer em definitivo, nem na ideia de "processo", nem em outra ideia qualquer em que, e por contradição, os termos "material" e "imaterial" se mantenham ilesos, e sigam convivendo, ainda que em suposta harmonia, ou cobertos de toda sorte de escusas ou da boa-fé de um senso crítico sobre a mesma.

É, portanto, sobre esta insistente polaridade que este artigo busca refletir. Para tanto, a argumentação que se segue inspira-se nas contribuições de dois autores separados por um século de distância, consideradas as suas datas de nascimento: um, do efervescente XIX, o outro, do conturbado século XX. Estamos falando de Gabriel Tarde (1843-1904), “o mais filósofo dos sociólogos, ou o mais sociólogo dos filósofos", como definiu Vargas (2007, p. 11), e do antropólogo contemporâneo Tim Ingold (2015), com quem iniciaremos as primeiras trocas em diálogo com duas experiências materialmente vividas, uma por uma artista guatemalteca, outra por mim.

Os fios argumentativos seguem seus alinhavos, de modo a agregar as reflexões de Tarde (2007) e, também, a discutir alguns pontos cegos vinculados ou mesmo decorrentes da dualidade em foco: de um lado, o mundo material, do outro, o que se costuma conceber enquanto imaterial e imaterialidade. 0 objetivo deste artigo é, pois, contribuir com possibilidades analíticas pouco convencionais e de natureza ética acerca do debate patrimonial contemporâneo.

\section{A matéria e dois casos de rebeldia}

No ano de 2010, a poetisa e artista visual guatemalteca Regina José Galindo doava ao mundo mais uma das suas incisivas expressões: a obra intitulada Looting. ${ }^{2}$ Nela, Galindo submete-se à perda voluntária de parte dos seus tecidos dentários - através de um desgaste

20 termo pode ser traduzido do inglês para o português como "pilhagem", e a descrição detalhada desta encontra-se disponivel na página eletrônica da artista em: http:// www.reginajosegalindo.com/. 
prospectado por um dentista da Guatemala - e, em substituição, recebe incrustações em "ouro nacional de mais alta pureza"3 naquelas cavidades abertas. Tempo depois, em Berlim, tais incrustações são removidas, e substituídas por outro material restaurador, uma vez que aquelas pequenas peças em ouro teriam outro destino.

O destino: as oito pequeninas formas em metal nobre seguiram à exposição museológica. A poética de base dessa obra é assim descrita na página eletrônica da artista: "por um lado, a conquista, a guerra, a política que devastou a terra, a exploração do solo, os humiIhados; por outro lado, o conquistador, aquele que comanda, o homem do mundo frio, aquele que levanta a mão e guarda o ouro". ${ }^{4}$ As fotos disponiveis neste mesmo domínio virtual testemunham todo o processo: desde a programada mutilação tecidual dos molares da artista ao acondicionamento das peças em uma espécie de relicário acrílico, onde estas repousam, tal como "objetos de arte", assentadas sob uma pequena almofada de veludo rubro.

Cerca de uma década depois, em um ponto mais abaixo do centro do continente americano, mais precisamente, na cidade de Salvador da Bahia, licencie-me a prestar uma singela homenagem a essa artista, ao tomar conhecimento dessa sua ação. No bojo de uma experiência de aprendizado cerâmico em um movimentado ateliê universitário, busquei expressar materialmente o espanto diante da obra daquela artista. Mais especificamente, tratouse de uma reprodução em cerâmica das oito unidades dentárias, as quais Galindo doou às reações das mais diversas, tantas quanto as interpretações humanas possam tocar.

3 Fragmento da descrição contida na página eletrônica da artista: http://www.reginajosegalindo.com/; minha tradução; acesso em: 5 nov. 2019.

4 Fragmento de descrição contida na página eletrônica da artista: http://www.reginajosegalindo.com/, minha tradução; acesso em: 5 de nov. 2019.
Tais processos interpretativos, em que pesem a densidade crítica que podem lograr, não são exatamente o foco desta reflexão, mas sim a sua dimensão material, mais precisamente, o que o título desta seção sugere enquanto rebeldia da matéria. Além de Looting, e como uma segunda experiência em relevo, miremos as experimentações cerâmicas que emergiram a partir do projeto que concebi e intitulei de Amostra: ensaio sobre (in)significâncias, então inspirado, em parte, por aquele trabalho de Galindo.

Em linhas bem sintéticas, busquei produzir em diferentes expressões escultóricas cerâmicas a mutilação dentária em seus múltiplos desdobramentos individuais e coletivos. Antes de prosseguir, cabem aqui algumas linhas de natureza autobiográfica, considerando dois aspectos relevantes desta abordagem ao escopo deste texto, a saber: um, da potência da narrativa autorreferente para fins da construção intersubjetiva de saberes; outra, de uma breve demarcação do território existencial de quem vos fala, e uma vez que uma porção do que chamo aqui de rebeldia da matéria emerge de experiências pessoais.

Ainda sobre o primeiro aspecto, e de acordo com Santos e Torga (2020, p. 140), é importante ressaltar o espaço e a legitimidade que o relato autobiográfico logram na contemporaneidade por razões diversas e, dentre elas, por pautar "uma subjetividade a revelar sua intimidade, a compartilhar com sua coletividade aquilo que a preocupa, que acredita, a vivência que resulta das marcas da ação do tempo, da história e das interações sociais sob o cotidiano de indivíduos em sua singularidade". E é justo nesta perspectiva que, ao desnudar a profunda e inquietante relação que tenho com o fenômeno da perda dentária, recrio, e recriamos juntos, a partir do olhar do outro, novos processos de produção de sentidos e significados em torno dos processos aqui em foco. 
Assim sendo, o espanto com a perda, ou mesmo, a possibilidade de perder dentes, chegou-me ainda quando dentes de leite eu possuía. Diferente do encantamento de Márquez (2003, p. 76) quem, em sua autobiografia, considerava ser um "privilégio mágico" este de poder "tirar" os dentes para "lavá-los, e deixá -los num copo d'água", referindo-se ali à sua cuidadora quando seguia ao leito para dormir, sofrimentos dentários e todos demais males bucais sempre me constrangeram em alguma medida. Recordo-me muito vivamente das dores de dente lancinantes que uma das minhas cuidadoras recorrentemente sofria: seu sorriso era quase sempre triste, quase completamente lacunar, e absolutamente contrastante com a pessoa de alma leve e alegre que era. Foi a partir dela que comecei a notar difusamente o quanto de identidade porta um sorriso. E, a partir disso, uma profusão de perguntas atravessavam-me com certa insistência: afinal, como "ser" inteiramente sem dentes? Ou ainda: como seria possível perder o que fora feito para durar?

Assim, sorrisos parcial ou completamente arruinados, dentes postiços, bocas desdentadas, em geral, quase sempre acompanhadas de injustas histórias de vida, não raro provocavam-me inquietantes interrogações. As perguntas de criança de certo me conduziram, junto a outros motivos de ordem prática, às minhas escolhas profissionais. Anos mais tarde, a graduação em Odontologia, todavia, só fez acirrar aquelas velhas inquietações, além de provocar novos constrangimentos. Recordo-me bem, ainda graduanda, de recusar-me a extrair um molar permanente de um jovem de 12 anos: a meu ver, a mutilação precoce não poderia ser uma regra.

Negando-me a este perverso modelo, segui questionando: mas como pode haver tantas tecnologias preventivas para o alcance de tão poucos? Ou como admitir tantas perdas que são quase que absolutamente evitáveis? O transitar pela área da saúde pública, mais precisamente, pelo campo da saúde coletiva, trouxe-me algumas respostas mais alentadoras. Contudo, e logo conclui, uma história secular de exclusão de cuidados e uma tradição assistencial essencialmente mutiladora não se resolveriam com um punhado de boas iniciativas políticas: a boca quase ou totalmente banguela ainda é uma realidade para muitos aqui, inclusive, mundo afora; e a escova e o creme dentais também não revolucionaram a saúde do sorriso tanto quanto podem alcançar.

De volta ao projeto em relevo neste texto, tratou-se, portanto, de uma releitura do fenômeno da perda massiva de dentes no país através de uma reelaboração crítico-poética dos indicadores nacionais que atestam tal fenômeno. Em termos práticos, passei a ler as estatísticas oficiais em termos de volumes de tecidos dentários perdidos: em um dado recorte temporal, algo em torno de 1 bilhão e 24 milhões de quilos relativos aos 16 milhões de desdentados totais no Brasil, segundo as estimativas do Instituto Brasileiro de Geografia e Estatística (IBGE) e do Ministério da Saúde, relativas à segunda década do século XXI. ${ }^{5}$

5 Números disponíveis na matéria do jornal 0 Globo, publicado em 06 de fevereiro de 2015, na reportagem da autoria de Carol Knoploch, na qual são referidos dados relativos à Pesquisa Nacional de Saúde do IBGE, em convênio com o Ministério da Saúde, realizada no ano de 2013. Este estudo contou com 80 mil visitas, em 1.600 municípios do Brasil, sendo, portanto, resultados representativos da perda dentária no país (KNOPLOCH, 2015). Isto é, trata-se de um recorte amostral da realidade do edentulismo em território nacional. Além desses números, artigos científicos tendem a evidenciar taxas de perda e de adoecimento dentários acima dos parâmetros e metas recomendados pela Organização Mundial da Saúde (OMS), a exemplo dos estudos de Cardoso et al. (2016) que apontam um decréscimo do edentulismo entre jovens e adultos no país, porém uma tendência de aumento expressivo entre idosos até o ano de 2040. Especificamente sobre aquela cifra, a de 1 bilhão e 24 milhões de quilos de tecido dentário perdido, cabe frisar que se trata de uma estimativa feita por mim, tratandose, portanto, de um cálculo aproximado e baseado em peso médio da unidade dentária perdida (algo em torno de 2,3 gramas é o peso médio de uma unidade 
Tentei, então, traduzir a dramaticidade desses números naquele fazer cerâmico, isto é, representar em barro a perda massiva de dentes no país, muitas vezes, de modo precoce, evitável e socialmente injusto. Trata-se de um projeto em aberto, em franca construção: há ainda muitos encaminhamentos possiveis e muitas peças a serem produzidas em torno daquela provocação. No entanto, as peças concluídas até aqui falam sobre isto, e o próprio processo de feitura tem mais a dizer a este texto.

Assim, a primeira porção de argila que chegou a minhas mãos pediu-me para ser um pequeno cubo, em realidade, mais próximo de uma forma retangular. De imediato, tornou-se um pequeno bloco maciço próximo a este formato. Naquela ocasião, mais atenta à dimensão técnica, a orientadora logo me advertiu: "cerâmica pede leveza, a argila precisa respirar leve". Dito isso, e em face daquele pequeno e adensado objeto, disse-me prontamente: "escave". E assim o fiz.

Desde este simples ato, e que logo se tornou tão corriqueiro, não demorou muito para eu perceber que, de fato, o barro tem as suas regras, mas também suas rebeldias. Os mais diversos manuais técnicos dizem isso ao seu modo, assim como a ciência é farta das explicações sobre o comportamento das ínfimas partes que fazem do barro, o barro. Todavia, entre teoria e prática, há um saber tácito, ou algo mesmo de inefável, que mais conhece quem faz: a mão na massa revela coisas que os escritos não alcançam. E o fazer cerâmico é assim: prenhe das tensões entre teoria e prática. Tais tensões me inquietaram - me inquietam -, e é também sobre isso este texto.

As provocações que o barro então me causou, sobretudo, para dar cabo de uma

dentária). Usualmente, a literatura técnica e científica da área odontológica emprega como unidade de referência o indivíduo, em termos de número de unidades perdidas por pessoa, e não o peso de tecidos dentários perdidos tal como aqui proposto. ideia imbuída da sua poética, forçaram-me a repensar o comportamento da matéria para além dos possiveis sentidos e significados que o projeto pretendia lograr mais adiante, enquanto produto acabado e disponivel ao olhar do outro. A partir disso, passei a perceber que as simbolizações ou representações a priori pretendidas podem ser facilmente traídas pela matéria em suas rebeldias. No caso, o fazer cerâmico tem exatamente disso: já partindo da complexa constituição da sua matéria-prima, perpassando os processos do manejo humano em suas intenções, até o seu mais ou menos imprevisivel comportamento forno adentro e vida afora.

Foram, então, exatamente essas inquietações que me levaram a buscar uma literatura que as acolhessem de forma menos fragmentada, isto é, uma abordagem talvez mais sensível à velha trama matéria-intenções (as minhas e as do material em seus processos físico-químicos ou de outra natureza). Assim, ao invés de me debruçar sobre a produção bibliográfica mais habitualmente referenciada quando se trata das grandes temáticas da "materialidade" e de "cultura material", decidi iniciar pelas “inflexões” propostas por Ingold (2015).

Este autor parte então do seguinte enigma: o desaparecimento dos próprios materiais na literatura que trata propriamente daquelas temáticas. Citando um dos autores que, no seu entender, vão além das "reflexões abstratas de filósofos e teoristas", assim delimita: "por materiais, refiro-me às coisas de que as coisas são feitas, e um inventário aproximado pode começar com algo como o seguinte, tirado da lista de conteúdo do excelente livro de Henry Hodges, Artefacts (Artefatos)", e são eles, "cerâmica; esmaltados; vidro e laqueados; cobre e ligas de cobre; ferro e aço; ouro, prata, cobre, chumbo e mercúrio; pedra; madeira; fibras e fios; têxteis e cestas; peles e couro", entre tantos outros. Isso posto, afirma Ingold que: 
Este volume pé no chão está repleto de informações sobre todos os tipos de materiais que os povos pré-históricos têm usado para fazer coisas. No entanto, nunca o vi referido na literatura sobre materialidade. Procurando pelas minhas prateleiras encontrei títulos como: The Mental and the Material (O mental e o material), de Maurice Godelier (1986); Mind, Materiality and History (Mente, materialidade e história), de Christina Toren (1999); Matter, Materiality and Modern Culture (Matéria, materialidade e cultura moderna), editado por Paul Graves-Brown (2000); Thinking through Material Culture (Pensando através da cultura material), de Karl Knappett (2005); Materiality (Materialidade), editado por Daniel Miller (2005); Material Cultures, Material Minds (Culturas materiais, mentes materiais), de Nicole Boivin (2008) e Material Agency (Agência material), editado por Lambros Malafouris e Karl Knappett (2008). Em estilo e abordagem, esses livros estão a um milhão de milhas da obra de Hodges. Seus compromissos, na sua maior parte, não são com as coisas tangiveis de profissionais e manufatureiros, mas com as reflexões abstratas de filósofos e teoristas. Eles discorrem, muitas vezes, em uma linguagem de impenetrabilidade grotesca, acerca das relações entre materialidade e uma série de outras qualidades igualmente insondáveis, que incluem agência, intencionalidade, funcionalidade, espacialidade, semiose, espiritualidade, encarnação. Procura-se em vão, no entanto, qualquer explicação compreensivel do que 'materialidade' realmente significa, ou qualquer explicação dos materiais e suas propriedades. Para entender a materialidade, ao que parece, precisamos ficar longe quanto possivel de materiais. (INGOLD, 2015, p. 50)

Antes que o leitor mais apressado se esquive, ou pior, abandone de vez esta perspectiva de argumentação, e mesmo antes de tocar no que tais ponderações teriam a ver com as incrustações de ouro de Galindo ou bilhões de tecidos dentários perdidos no Brasil, é prudente uma ressalva que o próprio Ingold (2015, p. 50) propõe no seu texto: "apresso-me a acrescentar que, obviamente, a maior parte da arqueologia é dedicada precisamente ao estudo de materiais e das maneiras como tenham sido utilizados em processos de produção; mesmo na antropologia, existe algum trabalho etnográfico sobre o assunto". E acresce este autor:

O meu ponto é simplesmente que este trabalho não parece interferir de forma significativa na literatura sobre materialidade e cultura material. Para estudiosos que dedicaram grande parte de suas energias ao estudo dos materiais, essa literatura se lê mais como uma rota de fuga para a teoria - uma que, confesso, eu mesmo já usei. Portanto, meu argumento é dirigido tanto para mim quanto a qualquer outra pessoa, e é parte de uma tentativa de superar a divisão entre trabalho teórico e prático. (INGOLD, 2015, p. 50 , grifos nossos).

E é justo esta tentativa, a "de superar a divisão entre trabalho teórico e prático", que mais se aproxima das motivações daquele projeto que, por sua vez, inspira as reflexões neste artigo. Os questionamentos daquele autor dirigem-se mais diretamente à antropologia em seus modos de lidar com a "cultura material" e da "materialidade", e cujo exemplo por ele oferecido é suficientemente claro: "um carpinteiro é alguém que trabalha com madeira, mas como Stephanie Bunn observou, a maioria dos antropólogos se contentaria em considerar o trabalho em termos da identidade social do trabalhador" ou, ainda, "das ferramentas que ele ou ela usa, da disposição da oficina, das técnicas empregadas, dos objetos produzidos e seus significados - tudo menos a madeira mesma" (INGOLD, 2015, p. 51).

Tais argumentos talvez não bastem a quem siga desconfiando que a cisão acima referida estaria muito bem resolvida uma vez que todas aquelas coisas materiais, ao menos em sua constituição física, caberiam às chamadas ciências exatas ou da natureza e, à filosofia e às humanidades, restaria todo aquilo intangível e que, ao que tudo indica, parece apenas apreciável se distanciado da sua existência palpável. No entanto, o desconforto com esta 
emblemática dualidade data, pelo menos, de mais de um século, no próprio bojo das ciências sociais e humanas, aqui em particular, nas reflexões de Gabriel Tarde, as quais recorreremos mais à frente.

Por ora, voltemos ao instigante desaparecimento dos materiais apontado por aquele último autor que, ao fazê-lo, passa a dialogar com outros atores para além da produção científica mais referenciada. Foi o caso de Stephanie Bunn, quem buscando uma "antropologia de sua experiência como artista e artesã, foi direcionada para a literatura sobre a cultura material" (INGOLD, 2015, p. 51). Entretanto, adverte este, "em nenhum lugar nessa literatura ela poderia encontrar qualquer coisa correspondente ao "pouco que fez"': isto é, "o trabatho com materiais que repousa no coração da sua própria prática como fabricadora" (BUNN, 1999, p. 15 apud INGOLD, 2015, p. 51).

Este relativo silenciamento com o qual Bunn se deparou pareceu-me bastante familiar naquilo que encontrei ao longo dos processos de produção das dezenas de dentes cerâmicos que fiz no interior do projeto aqui em foco. Possivelmente, Galindo poderia também tê-lo encontrado caso pretendesse explicar que, para além das representações e dos significados daquelas oito pequeninas peças em ouro, tratou-se, antes de tudo, de um corpo à serviço, isto é, foram tecidos dentários próprios, sadios e irregeneráveis, que se dissiparam naquela ação. Ou seja, em tese, poderíamos participar da mesma sensação de que "este fabricar é para Bunn, como o é para muitos artistas, um procedimento de descoberta: nas palavras do escultor Andy Goldsworthy, 'uma abertura para os processos da vida, dentro e em volta' (FRIEDMAN \& GOLDSWORTHY, 1990, p. 160)", conforme reflete Ingold (2015, p. 51). E é justo este "procedimento de descoberta" que encontra importantes limites em uma literatura que segue confortavelmente polari- zando matéria-espírito, isto é, processos mesmos da vida.

No caso da produção dos primeiros dentes cerâmicos, recordo-me bem uma das primeiras inquietações que me ocorreu: no afã de conciliar o comportamento da argila, em seus implicados aspectos técnicos, com os possíveis repertórios semânticos a partir dos produtos dali emergentes, passei a cogitar o quanto de afinidade aqueles minérios que a constituem teriam com os milhões de toneladas de minérios dos tecidos dentários perdidos Brasil adentro. É evidente que não estamos falando de uma relação direta entre aquelas poucas porções de argila e a dissipação destes minerais de origem dentária, onde quer que eles tenham ido parar (possivelmente no mesmo solo onde o barro se forma). Mas, em algum momento, estive sim pensando se haveria um outro destino para essa perda - diria até eticamente mais digno - a exemplo da sua incorporação a outras estruturas cerâmicas propriamente.

Em perspectiva afim, tomemos o caso da adição de cinzas de ossos bovinos na produção de corpos cerâmicos, o que já é uma prática estabelecida em alguns países, a exemplo de China, Inglaterra e Estados Unidos, em seus diversos fins, sobretudo, em função da biocompatibilidade que tais compostos logram alcançar. De certo, não parece ser apenas os fins simbólicos que, por si só, motivariam a fabricação em larga escala deste tipo cerâmico, mas sim questões mercadológicas e, talvez, ambientais o fariam. Tanto assim que a literatura acerca do tema, relativamente escassa, não enfatiza propriamente isso, mas tende mais a descrever processos físico-químicos da produção, e a apontar para as vantagens técnicas deste tipo cerâmico, incluindo, aspectos estéticos e de durabilidade.

No caso da adição de minerais de origem dentária a corpos cerâmicos, essa tecnologia, 
até então, não existe. Ao menos, ainda não há relato técnico ou científico de ampla divulgação sobre produções dessa natureza. Assim sendo, e de volta àquelas inquietações que tive ao tecer dentes cerâmicos, imaginando se tratar de uma ação impregnada de simbolismo e de representação do fenômeno do edentulismo em massa no Brasil, ocorreu-me pensar o quanto daquelas perdas poderiam retornar ao artefato produzido: será que assim cumpririam com menor fragmentação seus fins mais simbólicos e mais pragmáticos, incluindo, aqueles de reabilitação dentária a partir de corpos cerâmicos constituídos dos próprios tecidos de origem, ao menos, em parte?

Antes de qualquer risco de duvidosa interpretação disso, cabe aqui uma salutar ressalva de ordem ética: é evidente que não se cogita que tecidos humanos, no caso, de origem dentária, esteja à serviço de quaisquer interesses, sejam eles qual for. Mas a leitura é justamente a inversa: os interesses, sejam eles quais forem, devem se voltar ao que andamos perdendo de "processos de vida", ainda que em milimétricos volumes, como poeiras de nós que se dissipam no ar. Ou seja, no caso aqui, tecidos que se esvaem em suas variadas dinâmicas de perda, e que então se antecedem a qualquer intenção de uso ou fim. Em termos análogos, um coração só revive em alguém à sua espera quando este parou de bater em outro peito.

De volta àquela última indagação, ela mesma se desdobra em outra: a ideia proposta, fruto daquelas inquietações do fazer, ajudaria a romper aquela velha dualidade ou a endossa, ainda que involuntariamente? Posto de outro modo, estaria aí presente a esgarçada armadilha polarizadora: de um lado, abstrações e simbolizações, de outro, a concretude da vida como ela é, no caso aqui, dos materiais em si mesmos? Sem pretensões, ou mesmo, sem condições de um sim ou um não com alguma segurança, as perspectivas de reflexão que se abrem a partir daqui parecem mais distanciadas dos velhos vícios das explicações dicotômicas. Ou próximas de algo como já rebatia Gabriel Tard:

[...] se os corpos vivos [...] são máquinas, a natureza essencial dos únicos produtos e das únicas forças resultantes de seu funcionamento que nos são conhecidos até o fundo (sensações, pensamentos, volições), nos mostra que seus alimentos (carbono, azoto, oxigênio, hidrogênio, etc.), contêm elementos psíquicos ocultos. (TARDE, 2007, p. 71-72, grifos nossos)

Aqui, e antes que o leitor se atenha apenas à datada compreensão de corpo vivo enquanto "máquina", e, de fato, procederia assim admitir tal datação, a tônica do argumento em questão estaria justo na fonte comum onde espírito-matéria se alimentam: afinal, o mesmo carbono ou o oxigênio que constitui o objeto são aqueles que nos fazem seres sensiveis, pensantes, volitivos. Tarde (2007), parece arriscar mais do que isto: ao atribuir "elementos psíquicos ocultos", ou seja, elementos da anima aos supostos inanimados, tais como ao "carbono, azoto, oxigênio, hidrogênio, etc", propõe romper em definitivo a última ou a principal barreira entre matéria e espírito, isto é, a própria anima. Assim, para ele, "matéria é espírito, nada mais", sendo esta tese, inclusive, a "única que se compreende e que oferece realmente a redução exigida" (TARDE, 2007, p. 65).

Mais recentemente, e para Latour (2013, p. 11), ao revistar criticamente as "promessas da modernidade", conclui que a "nossa vida intelectual é decididamente mal construída". E avança esse autor: "a epistemologia, as ciências sociais, as ciências do texto, todas têm uma reputação, contanto que permaneçam distintas"; ou seja, "caso os seres que você esteja seguindo atravessem as três, ninguém mais compreende o que você diz" (LATOUR, 2013, p. 11). Lá atrás, para Tarde (2007), e em linhas bem breves, trata-se tão somente de uma 
questão do olhar, isto é: "esses elementos últimos aos quais chega toda ciência, o indivíduo social, a célula viva, o átomo químico, só são últimos da perspectiva de sua ciência particular" (TARDE, 2007, p. 57).

No compreender de Vargas (2007, p. 23), estaria posto neste olhar tardiano que "o animado e o inanimado se confundem in minimus", e este parece ser um dos pontos chaves da superação da dualidade que se pretende discutir em termos de "rebeldia" da matéria. A rebeldia aqui teria, então, o senso da contrariedade com as tendências antropocêntricas de leitura e de concepção da complexidade da vida, e também de uma persistente ilusão de controle absoluto da matéria em função das intencionalidades humanas. Antes disso, e se "o animado e o inanimado se confundem in minimus" (VARGAS, 2007, p. 23), haveria sim alguma coisa de matéria que dita certas regras antes ou, na melhor das hipóteses, simultaneamente às vontades e intenções humanas, tal como sugerem as reflexões de Gabriel Tarde.

Adiando mais um pouco o que "sociólogofilósofo" ou "filósofo-sociólogo" tem a nos dizer, voltemos à rebeldia da matéria, retomando o fio da meada com uma das questões substanciais proposta por Ingold (2015) no debate sobre materialidade: "se o meu corpo realmente participa do mundo material, então como pode o corpo-que-eu-sou se comprometer com esse mundo?". Antes, no entanto, é interessante conhecer o contexto da pergunta, que está justamente na crítica daquele autor a uma das várias tentativas de superação da polaridade entre teoria e prática, mais precisamente, entre o mundo material e a materialidade, no caso aqui, também a “imaterialidade”.

Particularmente dirigindo-se à proposição de Gosden (1999, p. 152) acerca de uma divisão didática do mundo material em "dois amplos componentes", isto é, "paisagem e artefatos", Ingold (2015) indaga se tudo que é "material" caberia mesmo ali, nesta pretensiosa dupla macro categorial. Neste bojo, uma das questões postas por ele seria: "onde, nesta divisão entre paisagem e artefatos, poderíamos colocar todas as diversas formas de vida animal, vegetal, fúngica e bacteriana"? (INGOLD, 2015, p. 52). E avança:

Será que a chuva pertence ao mundo material, ou apenas as poças que ela deixa nas valas e buracos? Será que a neve que cai participa do mundo material somente quanto pousa sobre o chão? Como engenheiros e construtores sabem todos muito bem, chuva e geada podem romper estradas e edifícios. Como então afirmar que estradas e edificios sejam parte do mundo material, se a chuva e a geada não o são? E onde poríamos o fogo e a fumaça, a lava incandescente e as cinzas vulcânicas, para não mencionar líquidos de todos os tipos, da tinta à água corrente. (INGOLD, 2015, p. 52)

Evidentemente, a lista é enorme, incluindo, o ar, a lua, o sol, as estrelas, conforme esse autor segue a desdobrando, e transitando entre críticas e possibilidades acerca de uma possível reconciliação entre o "mundo material" e a "materialidade". Nesse empenho, e em meio a tantas incertezas, fato é que "enquanto nadam neste oceano de materiais, os seres humanos, obviamente, desempenham um papel nas suas transformações", do mesmo modo "o fazem criaturas de todos os outros tipos", diz Ingold (2015, p. 57). E conclui em um ponto chave da sua reflexão e também para este texto que "muito frequentemente os seres humanos continuam a partir de onde não humanos param, como quando extraem a cera secretada pelas abelhas para fazer paredes dos alvéolos do favo de mel para posterior utilização no fabrico de velas" (INGOLD, 2015, p. 57).

Isso posto, e do mesmo modo, a lista de transformações de mundo partilhadas entre humanos e não humanos segue igualmente incomensurável, incluindo coisas como secreções, peles, osso, chifres, penas, esterco etc. No 
caso aqui em relevo, as transformações partilhadas estariam entre as poeiras de tecidos dentários humanos, que tendem a se dissipar no ar ou a seguir ralo abaixo dos gabinetes odontológicos, e a argila em processo de produções humanas a caminho de ser um artefato qualquer, inclusive, os próprios dentes para fins de reabilitação das perdas, se as pesquisas tecnológicas avançarem para isso. No caso de Galindo, por sua vez, e com o seu corpo "à serviço" da crítica visceral a que se propôs, é ali possivel vislumbrar um corpo "realmente participando do mundo material", portanto, um "corpo-que-ela-é" de fato e intensamente "comprometido com este mundo", tal como sugere a provocação acima de Ingold (2015).

Avançando nessa perspectiva, uma outra leitura daquele mesmo autor pode nos ajudar mais uma vez a pensar sobre a rebeldia da matéria ante as pretensões humanas, inclusive, aquelas que creem ser viável prescindir da própria matéria para falar algo em termos de uma suposta "imaterialidade" ou de uma cultura "imaterial" qualquer. Como visto até aqui, a contaminação pela matéria é inabalável: nem que seja de ar ou da atmosfera, a imaterialidade estará sempre plenamente preenchida, ou até enquanto a vida no planeta sobreviver à ação humana predatória, como diria Jonas (2006). Todavia, e tal como adverte aquele autor, "uma vez que o nosso foco está na materialidade dos objetos" e, acresço aqui, na suposta "imaterialidade" também, "é quase impossivel seguir as múltiplas trilhas do crescimento e transformação que convergem, por exemplo, na fachada de estuque de um edificio ou na página de um manuscrito" (INGOLD, 2015, p. 59, grifos do autor). E segue esclarecendo:

Essas trilhas são simplesmente varridas para debaixo do tapete de um substrato generalizado sobre o qual diz-se que as formas de todas as coisas são impostas ou inscritas. Insistindo em que demos um passo para trás, da materialidade dos objetos para as propriedades dos materiais, proponho que levantemos o tapete para revelar sob a sua superficie um emaranhado de meândrica complexidade, no qual - entre uma miríade de outras coisas - a secreção de vespas do bugatho apanhadas com ferro-velho, seiva de acácias, penas de ganso e peles de bezerro, e o resíduo de calcário aquecido se mistura com as emissões de suínos, bovinos, galinhas e abelhas. Pois materiais como estes não se apresentam como símbolos de alguma essência comum - materialidade - que dota cada entidade mundana com a sua inerente 'objetividade', ao contrário, eles participam dos processos mesmos de geração e regeneração contínua do mundo, do qual as coisas como manuscritos ou fachadas são subprodutos impermanentes. Portanto, escolhendo mais um exemplo ao acaso, ossos de peixe ferventes produzem um material adesivo, uma cola, e não uma materialidade típica de peixes nas coisas coladas. (INGOLD, 2015, p. 52, grifos nossos)

É justo este "levantar do tapete" de encontro à propriedade dos materiais um movimento necessário às tentativas de superação da dualidade matéria e materialidade e, como em destaque aqui, da matéria/i-matéria. Já os grifos ao final daquela última citação servem para nos alertar que, desde esse olhar, coisas produzem coisas e não "coisidades", isto é, matéria produz matéria, seja ela qual for, e não "materialidades" ou "imaterialidades". Inclusive, até as coisas que se julgam sem matéria tais como pensamentos, volições, valorações, representações, simbolizações, abstrações, entre outros - e como já dito, estão, pelo menos, prenhes de ar. Ao menos, enquanto este não for rarefeito, no caso, em virtude da própria ação antiética humana diante das coisas, como diz Jonas (2006), mas o deixemos para mais adiante.

\section{Outras rebeldias ou alguns pontos cegos da "imaterialidade"}

Na seção anterior, o foco esteve na reflexão da rebeldia da matéria, isto é, na sua insis- 
tência em se pronunciar entre as "materialidade" ou "imaterialidade", tal como pensadas, amplo senso, em uma literatura técnica e científica afim. A partir daqui os processos reflexivos sobre a rebeldia material buscam revelar alguns pontos cegos ainda passiveis de serem creditados à polaridade em relevo: as supostas dimensões material e imaterial do patrimônio.

Antes de avançar, uma importante ressalva deve ser feita: a de que a crítica que se busca aqui, mais de natureza teórico-conceitual, não contradiz ou desmerece todo o empenho e desdobramentos práticos em torno do que se alcançou em termos de fomento e/ou de salvaguarda de patrimônios mundo afora. Mas justo o contrário: os propósitos caminham muito mais no sentido de refletir o quanto daquela dicotomia endossa, sobretudo, em seus pontos cegos, os principiais desafios e limitações que incidem sobre a efetiva implementação das políticas culturais patrimoniais.

Nessa mesma perspectiva, Bengio et al. (2015, p. 19), ao refletir sobre "tensões" no Programa Nacional de Patrimônio Imaterial (PNPI), então vinculado ao Plano Nacional de Cultura, de 2010, interrogam-se sobre quais "demandas" e quais "efeitos produzidos" se verificam a partir dos movimentos em torno da efetivação de direitos no campo da cultura no Brasil com esta política, no caminhar da segunda década do século vigente. As conclusões destes autores, bem como as de outros neste mesmo viés de problematização, têm recaído no terreno comum das dificuldades em suas mais variadas naturezas. Assim, faltas ou insuficiências de toda ordem tendem ser a tônica: desde as que perpassam as ações mais burocrática e/ou institucional, a exemplo de certas incompatibilidades entre metodologias de inventariar possíveis candidatos à patrimonialização e a complexa realidade na qual se inserem, àquelas que dizem respeito ao supri- mento mesmo de recursos e insumos necessários aos processos (BENGIO et al., 2015; LEAL \& LEAL, 2012; SOUZA FILHO \& ANDRADE, 2012).

Nessa mesma perspectiva, e ainda a título de exemplo, o estudo desses últimos autores, acerca dos desafios da inventariação patrimonial de quilombolas em Alcântara, no Maranhão, aponta, dentre as diversas dificuldades, os "efeitos da separação arbitrária entre material e imaterial", de modo que "a caracterização do patrimônio imaterial dos quilombolas, nesse caso, depende e está relacionada à sua base material" (SOUZA FILHO \& ANDRADE, 2012, p. 92). Ou seja, o material e o "imaterial" são mesmo indissociáveis e, no caso, fazem os processos culturais perder o sentido dentro de uma lógica polarizadora. Isso posto, esses autores ainda sublinham o que chamam de "cultura do material", a qual imprime um "tipo de colonização do imaterial que a política institucional não conseguiu ainda resolver" (idem, p.92). Com isso, querem dizer que a excessiva abordagem materialista da patrimonialização acaba enfocando mais o produto do que o processo, isto é, o "saber - fazer", para o melhor uso do jargão.

A crítica daqueles autores é bastante compreensível e, de certo, endossada pela literatura afim, contudo, é possivel encontrar aí um dos pontos cegos aos quais esta seção se dedica. Trata-se daquele que decorre da própria dualidade em xeque: é, portanto, mais um subproduto da cisão materialidade/imaterialidade, mais precisamente vinculado ao uso corrente da noção de "processo" enquanto um recurso, quase que um subterfúgio, que supostamente resolveria aquela polaridade. Assim, no esteio deste uso mais genérico da ideia de "processo", por vezes, em detrimento de "produto", fato é que "estudos da chamada cultura material têm se centrado esmagadoramente nos processos de consumo em vez de nos de produção", assinala Ingold (2015, p. 59), 
apoiado em Miller (1995; 1998) e Olsen (2003). E avança aquele primeiro autor:

\begin{abstract}
Pois tais estudos tomam como seu ponto de partida um mundo de objetos que, por assim dizer, já se cristalizou a partir dos fluxos de materiais e suas transformações. Neste ponto os materiais parecem desaparecer, engolidos pelos objetos mesmos aos quais deram à luz. É por isso que comumente descrevemos materiais como 'brutos', mas nunca 'cozidos' - pois no momento em que se congelam em objetos eles já desaparecem. Por conseguinte, são os próprios objetos que captam a nossa atenção, não mais os materiais do que são feitos. É como se o nosso envolvimento material só começasse quando o estuque já endureceu na fachada ou a tinta já secou na página. Vemos o prédio e não o reboco das paredes; as palavras e não a tinta com a qual foram escritas. (INGOLD, 2015, p. 60 , grifos do autor)
\end{abstract}

Diante disso, a apreensão deste mundo de objetos já cristalizados pode explicar, ao menos em parte, aquela primazia do produto sobre o processo e, em especial, sobre os processos de produção; e, ao que tudo indica, isso parece não fazer muito bem aos recentes esforços de patrimonialização do "imaterial", sobretudo, do "saber - fazer", conforme discutido acima. Além disso, um outro ponto, que também parece embaçado, estaria nos riscos do "esquecimento" de que processo é também consumo, portanto, consumo de algo, ainda que "apenas" do ar que inspira e faz respirar o sujeito que sabe fazer. Dito de outro modo, a "imaterialidade" do saber fazer não é tanto imaterial assim, no limite, de imaterial não teria propriamente muita coisa.

Ademais, e ainda no bojo dos possiveis efeitos da dicotomia em termos políticos, sobretudo, em seus desdobramentos práticos, é sempre interessante manter a vigília sobre certos discursos. Assim, na seara do fomento ao campo da cultura e aos mais amplos e diversos interesses patrimoniais, convém se interrogar o quanto do discurso da imaterialida- de, mesmo que de forma bastante inconsciente, aprofunda o fosso entre matéria e “i-matéria", reforçando assim a falsa noção de que o suposto imaterial prescinda do material (aqui enquanto recursos variados), uma vez que estaríamos tratando afinal de um "saber - fazer" em abstrato, e não de matérias.

Em contraposição a tais tendências dicotômicas, um breve passeio sobre etimologias pode ser, por vezes, esclarecedor: assim como "patrimônio" remete, em seu prefixo, à palavra "pai", o termo "material" é uma "extensão do latim mater ('mãe')", sinaliza Ingold (2015, p. 61). Assim, materiais, enquanto "mater" de tudo que há, estão "longe de serem a coisa inanimada tipicamente imaginada pelo pensamento moderno", mas, "materiais, neste sentido original, são os componentes ativos de um mundo-em-formação" (INGOLD, 2015, p. 61). Assim sendo, não parece por um acaso ser mais fácil conceber sem titubeios a noção de "patrimônio material" do que aquele que supõe prescindir ou renunciar, ainda que parcialmente, da "mater", isto é, dos materiais que “onde quer a vida esteja acontecendo, eles estão incansavelmente em movimento - fluindo, se deteriorando, se misturando e se transformando" - acresce aquele mesmo autor (2015, p. 61).

Um último ponto cego estaria na linha de encontro da dimensão ética que a dualidade do material/imaterial pode comportar. Aqui, são as reflexões de Hans Jonas (2006) que mais atenderiam às premências desta discussão, mais precisamente, a partir do que ele concebe em torno do "princípio da responsabilidade". Este autor, ao revisar o pensamento filosófico ocidental acerca da ética, destaca que "todo o trato com o mundo extra-humano, isto é, todo o domínio da techne (habilidade) era - à exceção da medicina - eticamente neutro, considerando-se tanto o objeto quanto o sujeito de tal agir" (JONAS, 2006, p. 35). E avança: 
Do ponto de vista do objeto, porque a arte só afetava superficialmente a natureza das coisas, que se preservava como tal, de modo que não se colocava em absoluto a questão de um dano duradouro à integridade do objeto e à ordem natural em seu conjunto; do ponto de vista do sujeito porque a techne, como atividade, compreendia-se a si mesma como um tributo determinado pela necessidade e não como um progresso que se autojustifica como fim precípuo da humanidade, em cuja perseguição engajam-se o máximo esforço e a participação humanos. A verdadeira vocação do homem encontrava-se alhures. Em suma, atuação sobre objetos não humanos não formava um dominio eticamente significativo. (JONAS, 2006, p. 35 , grifos nossos)

Os grifos acima pretendem enfatizar o fato de toda ética tradicional ser antropocêntrica, segundo a ótica desse autor, uma vez que "a significação ética dizia respeito ao relacionamento direto de homem com homem, inclusive o de cada homem consigo mesmo" (JONAS, 2006, p. 35). Todavia, e especialmente a partir do crescente tecnológico sem precedentes em muitas das histórias da humanidade, emerge o imperativo do deslocamento daquele antropocentrismo, uma vez que "a promessa da tecnologia moderna se converteu em ameaça" para o próprio ser humano em virtude das suas danosas e potencialmente letais consequências (JONAS, 2006, p. 21).

Dito de outro modo, tal imperativo se traduz em: "age de tal maneira que os efeitos da tua ação sejam compativeis com a permanência de uma vida humana autêntica"; ou mesmo, "não ponhas em perigo a continuidade indefinida da humanidade na Terra", daí o citado "princípio da responsabilidade" (JONAS, 2006, p. 18). Isso posto, a linha de argumentação desse autor expõe a "crítica vulnerabilidade da natureza provocada pela intervenção técnica do homem": tanto e de tal forma a, de fato, ameaçar a própria continuidade da vida no planeta.
Mas, o que esta pauta excessivamente ecológica, “indigesta” ou, quiçá, inconveniente, teria a ver ou mesmo a dizer ao inócuo debate entre o que é e o que não é material ou “imaterial"? Uma indagação afim parece oportuna para pensar tal questão: a propósito, que lugar de conforto e de isenção as "imaterialidades" todas logram em um mundo em alta vulnerabilidade e materialmente posto em xeque? Dito de outro modo: o que o mundo etéreo das representações, das abstrações, das simbolizações, enfim, das imaterialidades todas, então desvencilhadas da sua concretude, endossa ou aprofunda, ainda que involuntariamente, as tantas mazelas do mero mundo mortal dos materiais?

Antes disso, as tendências de leitura parecem inversas, e perguntas podem daí emergir: seria pois o mundo materialista e das materialidades o "grande vilão" de uma vida eticamente viável, então naquela perspectiva de Jonas (2006), enquanto, do outro lado, o mundo das imaterialidades todas aprecia, em distância segura e confortável, tais processos de degradação e iniquidades, em que pesem as suas ferozes e contundentes capacidades críticas e reflexivas? A propósito, a própria noção “ética", ao menos como tradicionalmente pensada, não pertenceria apenas a este mundo isento e confortável das supostas imaterialidades?

Isso posto, e considerado aquele último ponto cego, como se comprometer eticamente a partir de uma perspectiva que fragmenta um mundo em sua matéria e espírito? Ou, aqui é o equivaleria a dizer que uma abordagem dicotômica de mundo não seria compativel com uma ética por inteiro, tal como aquela proposta por Jonas (2006). A esta altura, fica evidente que o acúmulo de questões tão complexas que se desdobram a partir da crítica à dualidade em relevo não se esgotaria nestas poucas linhas, mas o retorno ao foco deste texto pode sugerir algumas pistas. 
Assim, e já à guisa de conclusão, voltemos às contribuições de Tarde quando este persegue a inexorável marcha do infinitesimal, isto é, "a redução a uma só destas duas unidades, a matéria e o espírito" (TARDE, 2007, p. 53). Para esse autor, tal redução dirige-se ao "infinitamente pequeno", que é "a fonte e a meta, a substância e a razão de tudo", e é, portanto, onde não há mais como fragmentar ou discernir matéria-espírito: "tudo parte do infinitesimal e tudo a ele retorna" (TARDE, 2007, p. 60). Neste ponto, onde "matéria" e "imatéria" se fundem a tal ponto, e se afetam mutuamente, que sentido e, sobretudo, quais múltiplas consequências sucedem quando insistimos em partir da fragmentação?

$\mathrm{Na}$ leitura de Vargas (2007, p. 16), “quanto mais nos aproximamos do infinitamente pequeno mais encontramos seres completos e complexos"; e, potencialmente, a ciência estaria aí para "evidenciá-lo, enquanto progride multiplicando prodigiosamente os agentes do mundo" (VARGAS, 2007, p. 16). Nas próprias palavras de Tarde (2007, p. 65; p. 78), e em defesa de uma ciência radicalmente diferente daquela que tornou-se hegemônica e perigosamente fragmentada, há provas suficientes, e desde o século XIX, de que "a ciência tende a pulverizar o universo, a multiplicar indefinidamente os seres", e ainda ela, "após ter pulverizado o universo, acaba necessariamente por espiritualizar sua poeira".

Lido de outro modo, e mais confluente com o foco desta reflexão, é mesmo a poeira universal, ou isto que nos chega enquanto matéria que tudo constitui, que é prenhe de espírito, e que, segundo Tarde (1895), estaria passivel de leitura pela ciência. A propósito, a mesma molécula de oxigênio que respira nos tecidos de Galindo, ou naqueles milhões de tecidos dentários humanos, respira também em qualquer ínfima parte disto que consideramos "patrimônio da humanidade", usando mais uma vez do jargão. Contudo, para poder avançar nessa perspectiva, e não naquela que cartesianamente mutila matéria-espírito, com suas drásticas e nem sempre explícitas consequências, ou, como adverte Vargas (2007, p. 13), para se aproximar de "um conteúdo minimamente realista", é mesmo necessário "realizar um movimento desconcertante e admitir que há infinitamente mais agentes no mundo do que correntemente imaginam nossas ciências humanas" (VARGAS, 2007, p. 13).

É, portanto, sobre este mundo não fragmentado e revisto em sua pluralidade de agentes, inclusive, para além dos nossos irrefreáveis vícios antropocêntricos, que a reflexão e a ação sobre o patrimônio devem ser consideradas, conforme as provocações neste texto buscaram se aproximar a partir das abordagens acionadas. Do ponto de vista ético, e novamente concordando com Jonas (2006), é “a continuidade da mente com o organismo, do organismo com a natureza", que a ética "torna-se parte da filosofia da natureza", de modo que "somente uma ética fundada na amplitude do Ser pode ter significado" (JONAS, 2006, p. 17). Uma ética "fundada na amplitude do Ser", por sua vez, só pode prever um mundo menos fragmentado, um mundo por inteiro.

\section{Considerações finais}

As reflexões propostas neste texto partiram do que persegui problematizar em termos de uma rebeldia da matéria, em especial, da sua insistência em se sobrepor sobre o que se supõe sob absoluto controle das intenções e ações humanas. Deslocadas tais reflexões para o âmbito da discussão patrimonial, uma das questões centrais que se pretendeu levantar foi: mas o que há mesmo de imaterial em conceber, valorar, processar, saber fazer, transmitir? Ou ainda: quais efeitos do conceber "imaterialidades" descoladas, em alguma medida, da 
dimensão material que as sustentam em face aos complexos processos culturais?

Diante da complexidade de tais inquietações, é evidente que as linhas tecidas neste texto estão muito distantes de saturá-las razoavelmente, no entanto, busquei cumprir a contento o propósito de dialogar com abordagens pouco usuais no debate sobre patrimônio. Ou seja, em termos de contribuição a este debate, eis aqui uma aproximação a perspectivas que podem adensá-lo em algum grau, a exemplo do olhar de Tarde (2007), das contribuições de Ingold (2015) e da ética de Jonas (2006).

Esta última, a dimensão ética, bem como a revisão do seu conceber mais convencional, podem então ser tomadas como mote para outras reflexões que se desdobram em torno dos processos de patrimonialização. No caso deste texto, e ao enfocar as necessidades de superação da dualidade do material e do imaterial, o imperativo ético posto esteve (e está) no desafio da compreensão de "mundo por inteiro" enquanto uma noção a ser incorporada no debate técnico e científico em torno do patrimônio, e sobre a qual todo e qualquer ato de distinção deve partir e/ou se reportar. Além disso, o ínfimo e o plural deste "mundo por inteiro" deveriam interessar mais a fundo a política patrimonial em qualquer canto de um planeta em franca vulnerabilidade, ou disso que podemos considerar um ameaçado "patrimônio-planeta".

\section{Referencias}

BENGIO, Fernanda Cristine dos Santos; LEMOS, Flávia Cristina Silveira; FERRERI, Marcelo de Almeida; FERREIRA, Evelyn Tarcilda Almeida. A produção da cultura popular: tensões no Programa Nacional de Patrimônio Imaterial. Quaderns de Psicologia, v. 17, n. 1, p. 19-27, 2015. Disponivel em: <http://www.quadernsdepsicologia.cat/article/view/v17-n1-bengio-lemosferreri-etal/1203-pdf-pt>. Acesso em: 28 mai. 2020.
BUNN, Stephanie. The importance of materials. Journal of Museum Ethnography, v. 11, p. 15-28, 1999. Disponivel em: <http://www.jstor.org/stable/40793620?seq=1>. Acesso em: 28 mai. 2020.

CARDOSO, Mayra; BALDUCCI, Ivan; TELLES, Daniel de Moraes; LOURENÇO, Eduardo José Veras; NOGUEIRA JÚNIOR, Lafayette. Edentulismo no Brasil: tendências, projeções e expectativas até 2040. Ciênc. Saúde Coletiva, v. 21, n. 4, p.1239-1246, 2016. Disponivel em: <http://www.scielo.br/pdf/csc/v21n4/14138123-csc-21-04-1239.pdf >. Acesso em: 28 mai. 2020.

CHOAY, Françoise. Alegoria do Patrimônio. São Paulo: UNESP, Estação Liberdade, 2001.

FRIEDMAN, Terry \& GOLDSWORTHY, Andy. Hand to Earth. Leeds: W.S. Maney, 1990.

GOSDEN, Christopher. Anthropology and Archaeology: a changing relationship. Londres: Routledge, 1999.

HODGES, Henry. Artefacts: an introduction to early materials and technology. Londres: Duckworth, 1964.

INGOLD, Timothy. Estar vivo: ensaios sobre movimento, conhecimento e descrição. Pretópolis-RJ: Vozes, 2015.

JONAS, Hans. 0 principio da responsabilidade: ensaio de uma ética para a civilização tecnológica. Rio de Janeiro: Contraponto - Editora PUC Rio, 2006.

KNOPLOCH, Carol. Brasil tem 11\% da população sem nenhum dente. 0 Globo [on-line]. 2015. Disponivel em: https://oglobo.globo.com/sociedade/saude/ brasil-tem-11-da-populacao-sem-nenhum-dente-16325819. Acesso em: 6 jan. 2020.

LATOUR, Bruno. Jamais fomos modernos. São Paulo: Editora 34, 2013.

LEAL, Alessandra Fonseca; LEAL, Erika Adriana. Políticas públicas, culturas populares e patrimônio cultural imaterial: meios e alternativas. Curitiba. RA'E GA, v. 26, p. 247-69, 2012. Disponivel em: <http:// revistas.ufpr.br/raega/article/view/30161 >. Acesso em: 28 mai. 2020.

LIMA, Diana Farjalla Correia Lima. Museologia-Mu- 
seu e Patrimônio, Patrimonialização e Musealização: ambiência de comunhão. Bol. Mus. Para. Emílio Goeldi. Cienc. Hum., Belém, v. 7, n. 1, p. 31-50, jan./ abr. 2012. Disponivel em: <http:/ / www.scielo.br/pdf/ bgoeldi/v7n1/a04v7n1.pdf>. Acesso em: 28/05/2020

MÁRQUEZ, Gabriel García. Viver para contar. Rio de Janeiro: Record, 2003.

MILLER, Daniel. Acknowledging consumption. Londres: Routledge, 1995.

MILLER, Daniel. Why some things matter. In: MILLER, Daniel (ed.) Material cultures: why some things matter. Londres: UCL, 1998. p. 3-20.

OLSEN, Bjornar. Material culture after text: re-membering things. Norwegian Archaeological Review, v. 36, n. 2, p. 87-104, 2003. Disponivel em: <https:// www.researchgate.net/publication/228595177_Material_Culture_After_Text_Re-Membering_Things>. Acesso em: 28 mai. 2020

SANTOS, Yuri Andrei Batista; TORGA, Vânia Lúcia Menezes. Autobiografia e (res)significação. Bakhtiniana, v. 15 , n. 2, p. 119-44, abr./jun., 2020. Disponivel em: <https://www.scielo.br/pdf/bak/v15n2/21764573-bak-15-02-0119.pdf >. Acesso em: 28 mai. 2020.

SOUZA FILHO, Benedito; ANDRADE, Maristela de Paula. Patrimônio imaterial de quilombolas: limites da metodologia de inventário de referências culturais. Porto Alegre. Horizontes Antropológicos, ano 18, n. 38, p. 75-99, jul./dez., 2012. Disponivel em: < https:// www.scielo.br/pdf/ha/v18n38/04.pdf>. Acesso em: 28 mai. 2020.

SOUZA, Willian Eduardo Righini; CRIPPA, Giulia. O patrimônio como processo: uma ideia que supera a oposição material - imaterial. Porto Alegre. Em Questão. v. 17, n. 2, p. 237-51, jul./dez., 2011. Disponivel em: <http://seer.ufrgs.br/EmQuestao/article/ view/17609>. Acesso em: 28 mai. 2020.

TARDE, Gabriel. Monadologia e Sociologia: e outros ensaios. São Paulo: Cosac Naify, 2007.

UNITED NATIONS EDUCATIONAL, SCIENTIFIC, AND CULTURAL ORGANIZATION (UNESCO). Convenção para salvaguarda do patrimônio cultural e imaterial. 2003. Disponivel em: <http://unesdoc.unesco. org/images/0013/001325/132540por.pdf>. Acesso em: 12 nov. 2019.

VARGAS, Eduardo Viana. Gabriel Tarde e a diferença infinitesimal. In: TARDE, Gabriel. Monadologia e Sociologia - e outros ensaios. São Paulo: Cosac Naify, 2007.

Recebido em: 10.01.2020

Revisado em: 22.05.2020

Aprovado em: 28.05.2020

Ana Clara de Rebouças Carvalho é doutora em Saúde Pública pelo Instituto de Saúde Coletiva (ISC) da Universidade Federal da Bahia (UFBA). Professora adjunta do Departamento de Odontologia Social e Pediátrica da UFBA. Membro dos seguintes grupos de pesquisa cadastrados no Diretório do Conselho Nacional de Desenvolvimento Científico e Tecnológico (CNPq): Laboratório de Estudos sobre Crime e Sociedade (LASSOS) da UFBA; e Comunidade, Família e Saúde: sujeitos, contextos e políticas públicas (FASA) do ISC, da UFBA. E-mail: anaclarareboucas@gmail.com 